\title{
Construção e validação de cartilha educativa sobre exercícios pélvicos fundamentais para mulheres com incontinência urinária
}

\author{
Construction and validation of an educational booklet on fundamental pelvic exercises for \\ women with urinary incontinence
}

Construcción y validación de un folleto educativo sobre ejercicios pélvicos esenciales a mujeres con incontinencia urinaria

Íris Bisof Pontes', Elaine Aparecida Rocha Domingues ${ }^{2}$, Uiara Aline de Oliveira Kaizer ${ }^{3}$

RESUMO I A incontinência urinária feminina é uma condição multifatorial caracterizada pela perda involuntária de urina. Para seu manejo, é necessário o fortalecimento da musculatura do assoalho pélvico. Logo, a orientação por meio de material educativo disponível é uma ferramenta essencial para facilitar a transmissão do conteúdo e a adesão da população. Assim, o objetivo do trabalho foi desenvolver e validar uma cartilha educativa sobre exercícios pélvicos fundamentais para mulheres com incontinência urinária. Estudo metodológico, submetido a seis avaliadores experts na área, para a validade de conteúdo do material com o uso do Índice de Validade de Conteúdo (IVC). Posteriormente foi aplicado em 30 mulheres usuárias do Sistema Único de Saúde (SUS) e que realizavam acompanhamento ginecológico nas unidades de saúde para validação com a população-alvo. O estudo foi aprovado pelo Comitê de Ética em Pesquisa local sob o parecer n 4.099.724. O IVC da cartilha educativa variou de 0,71 a 1,00. Os especialistas fizeram observações referentes à aparência e ao conteúdo do material, as quais foram acatadas para a versão final. No pré-teste, as mulheres entenderam as imagens e o texto, 83,3\% julgaram a capa como chamativa e todas concordaram que a sequência, a estrutura organizacional e a construção das frases estavam adequadas. As ilustrações foram de fácil compreensão e 100\% afirmaram que foram totalmente abordados os assuntos necessários; a grande maioria (96,6\%) relatou motivação para leitura. A cartilha confeccionada mostrou-se adequada para orientação de mulheres com incontinência urinária, pelo seu conteúdo coerente com a realidade e com a necessidade de saúde. Descritores | Incontinência Urinária; Estudos de Validação. Educação em Saúde. Material de Ensino.

ABSTRACT | Female urinary incontinence is a multifactorial condition characterized by involuntary urinary loss. For its control, strengthening the pelvic floor muscles is necessary. Thus, the guidance provided through available educational material is an essential tool to facilitate the dissemination of knowledge and acceptance by the population. The study aims to create and to validate an educational booklet on fundamental pelvic exercises for women with urinary incontinence. This is a methodological study that was submitted to six expert evaluators in the area, for the content validity of the material using the Content Validity Index (CVI). Afterward, for validation with the target population, the booklet was applied to 30-women users of the Brazilian Unified Health System (SUS) and who underwent gynecological monitoring in health units. The $\mathrm{CVI}$ of the educational booklet ranged from 0.71 to 1.00. The evaluators made observations regarding the appearance and content of the booklet, which were accepted for the final version. In the pretest, women understood the images and the text, $83.3 \%$ of them judged the cover as attractive and all women agreed that the sequence, organizational structure, and understanding of the sentences were adequate.

PPrefeitura Municipal de Sorocaba - Sorocaba (SP), Brasil. E-mail: iris.bisof@gmail.com. ORCID-

2Universidade Vale do Rio Verde - Três Corações (MG), Brasil. E-mail: elainerocha.contato@gmail.com. ORCID-0000-0002-7589-2344. ${ }^{3}$ Prefeitura Municipal de Sorocaba - Sorocaba (SP), Brasil. Unicamp - Campinas (SP), Brasil. E-mail: uiara_oliveira@hotmail.com. ORCID-0000-0002-9115-8043. 
The illustrations were easy to understand and 100\% agreed that the necessary subjects were fully addressed and the majority (96.6\%) were motivated to read. The elaborated instrument proved to be effective for its use, because it meets the reality and the health need. Keywords I Urinary Incontinence; Validation Studies; Health Education; Teaching Material.

RESUMEN | La incontinencia urinaria femenina es una afección multifactorial caracterizada por la pérdida involuntaria de orina. Para su tratamiento, es necesario fortalecer los músculos del suelo pélvico. Para ello, la orientación mediante material educativo disponible es una herramienta fundamental para facilitar la transmisión de contenidos y la adherencia de la población al tratamiento. Ante esto, el objetivo de este trabajo fue desarrollar y validar un folleto educativo sobre ejercicios pélvicos esenciales a las mujeres con incontinencia urinaria. Este es un estudio metodológico, presentado a seis expertos en el área, para la validez de contenido del material utilizando el Índice de Validez de Contenido (IVC). Posteriormente, para validarlo se aplicó a 30 usuarias del Sistema Único de Salud (SUS) que se encontraban en seguimiento ginecológico en las unidades de salud. El estudio fue aprobado por el Comité de Ética en Investigación local bajo la opinión n. 4.099.724. El IVC del folleto educativo osciló entre 0,71 y 1,00. Los expertos formularon observaciones sobre el aspecto y los contenidos del material, los cuales fueron aceptados para la versión final. En el pretest, las mujeres entendieron las imágenes y el texto, el 83,3\% juzgaron Ilamativa la portada y todas coincidieron en que la secuencia, la estructura organizativa y la construcción de las frases estaban adecuadas. Las ilustraciones fueron fáciles de entender en el folleto, que abarcó el $100 \%$ de los temas esenciales; y la mayor parte (96,6\%) de ellas reportaron motivación para leerlo. El folleto elaborado resultó ser adecuado para orientar a las mujeres con incontinencia urinaria, por sus contenidos acordes con la realidad y la necesidad de salud de esta población

Palabras clave | Incontinencia Urinaria; Estudios de Validación; Educación en Salud; Material de Enseñanza.

\section{INTRODUÇÃO}

A Sociedade Internacional de Continência (ICS) define que qualquer perda urinária involuntária determina uma condição de incontinência urinária (IU) ${ }^{1}$. Ela pode ser classificada em subtipos: incontinência urinária de esforço (IUE), em que ocorre a perda urinária por conta de esforços físicos como tossir; incontinência urinária de urgência (IUU), em que a perda urinária se dá em conjunto com a sensação forte de urinar; e incontinência urinária mista (IUM), em que acontecem as duas situações ${ }^{2}$.

Estima-se que 200 milhões de pessoas são acometidas com IU, independentemente do gênero, e que a taxa de prevalência em mulheres é de $69 \%$, ratificando uma relação de ocorrência de duas mulheres para um homem. De acordo com a estimativa, mais de $50 \%$ de mulheres que se queixam do problema não procuram consultas relacionadas ao assunto ${ }^{3}$. O desconhecimento sobre a patologia e seu tratamento tem apontado um grave problema de saúde pública ${ }^{1}$.

A IU constitui uma condição multifatorial frequente que afeta muitas mulheres, levando-as a incômodos e constrangimentos, impactando negativamente a qualidade de vida delas. Nota-se a importância de conhecer e promover o tratamento precoce com o intuito de prevenção das alterações e melhora da qualidade de vida $(\mathrm{QV})^{2}$.
Quando as mulheres referem as queixas de disfunções do assoalho pélvico, utilizam como porta de entrada a Atenção Primária à Saúde (APS) do Sistema Único de Saúde (SUS), primeiro nível de atenção à população ${ }^{4}$. É ali que ocorre a base da prioridade da saúde pública, pois acontecem a prevenção desse agravo e a possível minimização com ajuda de profissionais capacitados ${ }^{4}$.

Dentre os profissionais da APS, o fisioterapeuta que atua na saúde da mulher está habilitado a realizar intervenções na prevenção de patologias e tratamento dos agravos, além de ser um educador e promotor de saúde. Uma das ações que se destacam na esfera de educador quando da abordagem às mulheres com disfunções urinárias diz respeito às orientações e abordagens cinéticofuncionais, a fim de evitar mau prognóstico em relação à QV, advindo da dimensão física, psicológica e emocional ${ }^{5,6}$.

Nesse contexto de atenção primária, uma importante ferramenta de educação em saúde são os chamados materiais educativos, como manuais, folhetos, fôlderes, livretos e cartilhas. De caráter mais ampliado, auxiliam no tratamento e na prevenção de agravos, constituindo uma forma efetiva e de baixo custo para a manutenção das condutas terapêuticas. Podem abranger grande número de pessoas e desenvolver nos indivíduos o senso da responsabilidade e de autonomia; são alternativas viáveis para informação, sensibilização da população e promoção do autocuidado ${ }^{7,3,8}$. 
Dessa maneira, o objetivo deste trabalho foi construir e validar uma cartilha educativa sobre exercícios pélvicos fundamentais para mulheres que sofrem com queixas de perdas urinárias.

\section{METODOLOGIA}

Trata-se de um estudo metodológico, que se destaca por ser investigativo, organizacional e analítico com o intuito de construir, validar e avaliar instrumentos ${ }^{9}$. Ele foi dividido em duas etapas: construção da cartilha educativa e validação de conteúdo; e pré-teste.

Na primeira etapa foi realizado um levantamento de dados da literatura sobre o tema, nas línguas inglesa e espanhola, em cinco bases de dados: Literatura Latino-Americana e do Caribe em Ciências Sociais e da Saúde (Lilacs), Scientific Electronic Library OnLine (Scielo), Biblioteca Virtual em Saúde (BVS), Physiotherapy Evidence Database (PEDro) e US National Library of Medicine (Pubmed). Utilizaram-se os seguintes descritores: incontinência urinária; estudos de validação; educação em saúde; e material de ensino.

Em seguida, a cartilha educativa foi desenvolvida de acordo com as orientações sobre concepção e eficácia de materiais didáticos, levando-se em conta conteúdo, linguagem, organização, design, gravuras, aprendizagem e motivação ${ }^{10}$.

Foram utilizados como referencial teórico para o tratamento conservador os exercícios de Kegel, pois, na década de 1950, Arnold Kegel, médico ginecologista, foi pioneiro ao introduzir o treinamento da musculatura do assoalho pélvico feminino para tratar a incontinência urinária nessa população ${ }^{3}$.

Após a construção da cartilha, foi realizada a validação de conteúdo por especialistas do assunto, os quais avaliaram aparência, abrangência, pertinência e clareza dos itens e concordância entre eles ${ }^{9}$. A validade de conteúdo é uma etapa importante para a construção de materiais educativos ou adaptações de medidas; é a capacidade do instrumento de realizar o propósito almejado.Já a abrangência indica se o domínio e/ou conceito foi adequadamente resguardado pelos itens e se as dimensões foram contempladas. A pertinência indica se há relação entre os itens e seus conceitos para atingir os objetivos estabelecidos. Por fim, a clareza é a capacidade de o material ser compreensível e expressar de maneira adequada sua função/finalidade ${ }^{9,11}$.

As variáveis da cartilha educativa analisadas foram: linguagem-pertinência, linguagem-abrangência, linguagem-clareza, layout-pertinência, layout-clareza, ilustração-pertinência e ilustração-clareza. A pertinência está relacionada aos conceitos das questões para saber se eles refletem aos conceitos envolvidos, se são relevantes à situação e adequados ao objetivo proposto; a clareza diz respeito à redação dos itens, se estes expressam apropriadamente o que se deseja medir e se traduzem fielmente o conceito desejado; e a abrangência se refere às informações suficientes para atingir o objetivo de cada tópico ${ }^{12}$.

Foi escolhido um comitê composto por seis juízes, dos quais três de cada categoria profissional - enfermeiro estomaterapeuta e fisioterapeuta urogineco-funcional/Saúde da Mulher -, obedecendo aos critérios para o número de juízes ${ }^{13}$. Eles foram convidados por e-mail e receberam a versão do instrumento. A cada um também foi encaminhado um questionário específico para realizar a avaliação.

Um protocolo de julgamento com seis itens foi elaborado para avaliação da cartilha pelos juízes e a análise teve a concordância e a relevância de cada item. Os dados foram codificados e verificados pelo software de estatística Excel; para a validação de conteúdo, utilizou-se o índice de validade de conteúdo (IVC), método que emprega uma escala de pontuação que varia de 0 a 4 de acordo com as respostas dos juízes: 1 (irrelevante), 2 (pouco relevante), 3 (realmente relevante) e 4 (muito relevante) ${ }^{9}$.

Os itens que receberam pontuação 1 ou 2 foram revisados ou eliminados. Para cálculo do IVC, utilizouse a seguinte fórmula: [IVC: número de respostas “3” ou "4" / número total de respostas]. Considerou-se valor aceitável o IVC maior ou igual $0,80^{9}$.

Devido à necessidade de estabelecer parâmetros para a seleção dos juízes, recorreu-se ao sistema de classificação de juízes em que foram selecionados profissionais com os seguintes critérios: teses ou dissertações na área; artigos científicos sobre o tema; participação em grupos de pesquisa e bancas de especialização; docência na área de IU; e atuação prática ${ }^{14,15}$.

A segunda etapa foi o pré-teste, envolvendo a populaçãoalvo, com o instrumento na versão final após a sugestão dos juízes, a fim de verificar a clareza, a compreensão e a relevância do conteúdo que a cartilha educativa oferecia. As perguntas se referiram à capa, layout, entendimento das frases, ilustrações e motivação para leitura.

A amostra contou com a participação da população feminina e usuária do SUS de duas unidades de Estratégia de Saúde da Família (ESF) de um município do interior do estado de São Paulo, constituindo um total de 30 mulheres. Os critérios de inclusão foram: mulheres acima de 18 anos, alfabetizadas, usuárias do SUS e que realizavam acompanhamento ginecológico nas referidas 
unidades. Já os de exclusão consistiram em: mulheres que estavam no período gestacional, que tomavam algum medicamento para a IU e que tinham algum histórico de cirurgia para fins de tratamento da IU.

Os dados foram coletados pela pesquisadora no período de 30 de setembro a 30 de outubro de 2020 , após autorização da administração do local. As abordagens ocorreram em ambiente privado na unidade de saúde, respeitando os preceitos éticos da Resolução n ${ }^{\circ}$ 466/2012. Foram adotadas as medidas de segurança em saúde para proteger os participantes e pesquisadores em época de pandemia. Todas assinaram o termo de consentimento livre e esclarecido (TCLE).

\section{RESULTADOS}

A primeira etapa consistiu na elaboração e na validação do conteúdo do instrumento. $O$ processo de criação se baseou na consulta à literatura nacional e internacional quanto aos principais aspectos a serem avaliados entre as mulheres com IU.

A composição dos juízes foi de seis especialistas na área de formação de fisioterapia da saúde da mulher: um, que atua tanto na área de fisioterapia da saúde da mulher quanto na de enfermagem estomaterapia, e dois na área de enfermagem estomaterapia. A maioria foi do gênero feminino (83\%), com média de idade de 42 anos, doutores, com ocupação atual em ambulatórios e instituições de ensino superior; o tempo de formação em média foi de 16,6 anos.

Em relação às sugestões, os juízes destacaram itens referentes ao design das imagens, textos e composição. Disso resultou uma cartilha com 24 páginas, 14 ilustrações com cores flats com saturação alta e compostas por formas simples para fácil leitura, em formato de livreto com dois grampos no meio.

O IVC da cartilha educativa variou de 0,71 a 1,00 (Tabela 1).

Depois da confecção da versão final da cartilha, o material foi submetido ao pré-teste, do qual participaram as mulheres em acompanhamento ginecológico nas unidades de saúde. Verificou-se que a maioria se apresentava na faixa etária de 30 a 49 anos (média de 42,5 anos, desvio-padrão 8,9), com ensino médio completo $(36,6 \%)$, dois filhos $(43,3 \%)$, histórico de parto cesáreo (60\%), índice de massa corporal entre 25,0 e 29,9 (43,3\%), sem constipação intestinal (70\%), sem hábitos tabagistas (100\%) e com consumo de cafeína $(93,3 \%)$.

Quadro 1. Síntese da análise qualitativa das alterações sugeridas pelos juízes da pesquisa relacionadas ao manual de IU

\begin{tabular}{|c|c|c|}
\hline Original & Sugestão dos juízes & Decisão \\
\hline $\begin{array}{l}\text { Capa com o título Exercícios pélvicos } \\
\text { fundamentais para mulheres com } \\
\text { incontinência urinária }\end{array}$ & $\begin{array}{l}\text { Trocar a imagem da capa para uma pelve em } \\
\text { evidência. } \\
\text { Trocar o título para Exercícios para o assoalho pélvico: } \\
\text { prevenção e tratamento da incontinência urinária. }\end{array}$ & $\begin{array}{l}\text { Título - Exercícios para o assoalho pélvico: } \\
\text { prevenção e tratamento da incontinência urinária } \\
\text { na mulher. }\end{array}$ \\
\hline Apresentação da cartilha & Colocar uma figura que represente a mulher com IU. & $\begin{array}{l}\text { Substituída a figura representando uma mulher } \\
\text { com IU. }\end{array}$ \\
\hline $\begin{array}{l}\text { Definição da IU: "A incontinência } \\
\text { urinária é uma perda de urina de } \\
\text { maneira involuntária, ou seja, a } \\
\text { pessoa não consegue controlar o xixi } \\
\text { e acaba saindo contra a sua vontade". }\end{array}$ & $\begin{array}{l}\text { Adicionar a descrição da Sociedade Internacional de } \\
\text { Continência. }\end{array}$ & $\begin{array}{l}\text { Adicionada a descrição da Sociedade Internacional } \\
\text { de Continência. }\end{array}$ \\
\hline \multirow[t]{2}{*}{$\begin{array}{l}\text { Fatores de risco: "Alguns hábitos ou } \\
\text { características nos deixam mais fáceis } \\
\text { de ter a incontinência urinária". }\end{array}$} & $\begin{array}{l}\text { "A incontinência urinária pode ocorrer por diferentes } \\
\text { causas", além de ser corrigido o alinhamento/ } \\
\text { espaçamento da página. }\end{array}$ & $\begin{array}{l}\text { Adicionado "A incontinência urinária pode ocorrer } \\
\text { por diferentes causas", além de corrigido o } \\
\text { alinhamento/espaçamento da página. }\end{array}$ \\
\hline & Adicionar uma página para apresentar os três tipos de IU. & $\begin{array}{l}\text { Adicionada uma página para apresentar os três } \\
\text { tipos de IU. }\end{array}$ \\
\hline $\begin{array}{l}\text { Na página sobre a explicação da IUE: } \\
\text { "É aquela que ocorre a perda do xixi } \\
\text { quando realiza algum esforço como } \\
\text { tossir, espirrar e levantar objetos } \\
\text { pesados". }\end{array}$ & $\begin{array}{l}\text { Substituir por "É aquela que ocorre a perda do xixi } \\
\text { quando realizamos algum esforço como tossir, espirrar } \\
\text { e levantar objetos pesados". }\end{array}$ & $\begin{array}{l}\text { Substituído por "É aquela que ocorre a perda do } \\
\text { xixi quando realizamos algum esforço como tossir, } \\
\text { espirrar e levantar objetos pesados". }\end{array}$ \\
\hline $\begin{array}{l}\text { Na página sobre a explicação da IUU: } \\
\text { "a Incontinência Urinária de Urgência } \\
\text { é uma vontade repentina e forte de } \\
\text { fazer xixi". }\end{array}$ & $\begin{array}{l}\text { Substituir por "É a perda involuntária de urina } \\
\text { precedida de um forte desejo de urinar". } \\
\text { Substituir a ilustração por outra mais representativa. }\end{array}$ & $\begin{array}{l}\text { Substituído por "É a perda involuntária de urina } \\
\text { precedida de um forte desejo de urinar". } \\
\text { Substituída a ilustração por outra mais } \\
\text { representativa. }\end{array}$ \\
\hline $\begin{array}{l}\text { Na página sobre a explicação da IUM: } \\
\text { "ocorre as duas situações anteriores". }\end{array}$ & $\begin{array}{l}\text { Substituir por "é a perda involuntária de urina ao } \\
\text { esforço e precedida de um grande desejo de urinar". } \\
\text { Substituir a ilustração por outra mais representativa. }\end{array}$ & $\begin{array}{l}\text { Substituído por "é a perda involuntária de urina ao } \\
\text { esforço e precedida de um grande desejo de urinar". } \\
\text { Substituída a ilustração por outra mais } \\
\text { representativa. }\end{array}$ \\
\hline
\end{tabular}


Quadro 1. Continuação

Original

Na seção sobre consequência da IU: "as consequências são muitas".

Na página de explicação sobre o assoalho pélvico: "Vamos conhecer o corpo feminino", "Se colocarmos um espelho para ver a parte da região íntima da mulher, é isto que será observado".

Na segunda página, que explica o assoalho pélvico: "Vamos conhecer o corpo feminino".

"Na parte de dentro...".

Na primeira página, que explica os exercícios que podem ser realizados.

Na segunda página, que explica os exercícios que podem ser realizados.

Na terceira página, que explica sobre os exercícios que podem ser realizados.

Na quarta página, que explica os exercícios que podem ser realizados.

Na página sobre hábitos.

Na página sobre o aviso.

\section{Sugestão dos juízes}

Substituir por "Os efeitos da incontinência urinária na vida das mulheres são muitas...".

Substituir por "Vamos conhecer os músculos do assoalho pélvico?".

Substituir por "Esses músculos fazem parte da camada muscular profunda da vagina. Quando a gente coloca um espelho para visualizar a vagina, nós conseguimos visualizar".

Substituir por "Vamos conhecer os músculos do assoalho pélvico?"

Substituir por "Na parte de baixo...".

Solicitar a explicação da função de intestinos, útero e bexiga.

Substituir por "Para melhorar o problema de perda urinária existem exercícios para fortalecer os músculos do assoalho pélvico que podem ser realizados diariamente".

Substituir por "Tente contrair os músculos ao redor do ânus; durante a expiração, faça força de segurar cocô; contraia também a musculatura como se estivesse segurando o xixi, mantenha a contração de 6 a 10 segundos; descanse por 10 segundos, e realize de 8 a 12 contrações por vez".

Substituir por "Tente realizar em outras posições a contração do assoalho pélvico apreendida".

Sugestão de transcrição do comando próximo da ilustração.

Substituir para "Tente realizar este exercício". Sugestão de mudança do comando para "Com o bumbum apoiado no chão, contraia os músculos do assoalho pélvico como se estivesse segurando um pum, eleve o quadril ainda segurando o pum por 6 a 10 segundos, retorne à posição inicial e relaxe por 10 segundos. Realize de 8 a 12 contrações por vez. Preferencialmente, 3 vezes ao dia".

Substituir por "Tente realizar este exercício".

Sugestão de mudança do comando para "Com uso de uma bola média entre os pés sem apertar, contraia os músculos do assoalho pélvico como se estivesse segurando um pum, com as pernas esticadas no chão, levante as pernas esticadas ainda fazendo a contração. Depois que chegar à altura que conseguir, abaixe as pernas, relaxando. Realize de 8 a 12 contrações por vez. Preferencialmente, realize 3 vezes ao dia".

Substituir por "terapia comportamental". Sugestão de "Podemos mudar alguns hábitos para melhorar a incontinência urinária: além dos exercícios para fortalecimento dos músculos do assoalho pélvico, é necessário realizar mudanças de comportamentos da nossa rotina de vida para tratar os sintomas de perda de urina".

Substituir por "Atenção".

Sugestão de "Esta cartilha não substitui a avaliação do assoalho pélvico, assim como o acompanhamento com um profissional de saúde especializado. Caso você tenha alguma queixa de perda urinária, é importante que você procure um profissional de saúde para uma consulta em que ele possa avaliar as condições do seu assoalho pélvico e mediar a força dessa musculatura. Sempre que precisar, vá até a unidade básica de saúde mais próxima para verificar esta e outras condições de saúde".
Decisão

Substituído por "Os efeitos da incontinência urinária na vida das mulheres são muitos..."

Substituído por "Vamos conhecer os músculos do assoalho pélvico?".

Substituído por "Esses músculos fazem parte da camada muscular profunda da vagina. Quando a gente coloca um espelho para visualizar a vagina, nós conseguimos visualizar".

Substituído por "Vamos conhecer os músculos do assoalho pélvico?".

Substituído por "Na parte de baixo...".

Adicionada a explicação da função de intestinos, útero e bexiga.

Substituído por "Para melhorar o problema de perda urinária existem exercícios para fortalecer os músculos do assoalho pélvico que podem ser realizados diariamente".

Substituído por "Tente contrair os músculos ao redor do ânus; durante a expiração, faça força de segurar cocô; contraia também a musculatura como se estivesse segurando o xixi, mantenha a contração de 6 a 10 segundos; descanse por 10 segundos, e realize de 8 a 12 contrações por vez".

Substituído por "Tente realizar em outras posições a contração do assoalho pélvico apreendida". Transcrito o comando próximo da ilustração.

Substituído por "Tente realizar este exercício" Mudança do comando para "Com o bumbum apoiado no chão, contraia os músculos do assoalho pélvico como se estivesse segurando um pum, eleve o quadril ainda segurando o pum por 6 a 10 segundos, retorne à posição inicial e relaxe por 10 segundos. Realize de 8 a 12 contrações por vez. Preferencialmente, 3 vezes ao dia".

Substituído por "Tente realizar este exercício". Mudança do comando para "Com uso de uma bola média entre os pés sem apertar, contraia os músculos do assoalho pélvico como se estivesse segurando um pum, com as pernas esticadas no chão. Levante as pernas esticadas ainda fazendo a contração. Depois que chegar à altura que conseguir, abaixe as pernas, relaxando. Realize de 8 a 12 contrações por vez. Preferencialmente repita 3 vezes ao dia".

\section{Substituído por "terapia comportamental".} Acatada sugestão de "Podemos mudar alguns hábitos para melhorar a incontinência urinária: além dos exercícios para fortalecimento dos músculos do assoalho pélvico, é necessário realizar mudanças de comportamento da nossa rotina de vida para tratar os sintomas de perda de urina".

Substituído por "Atenção".

Acatada sugestão de "Esta cartilha não substitui a avaliação do assoalho pélvico, assim como o acompanhamento com um profissional de saúde especializado. Caso você tenha alguma queixa de perda urinária, é importante que você procure um profissional de saúde para uma consulta em que ele possa avaliar as condições do seu assoalho pélvico e mediar a força dessa musculatura. Sempre que precisar, vá até a unidade básica de saúde mais próxima para verificar esta e outras condições de saúde". 
Tabela 1. IVC pelos juízes especialistas, SP (2020)

\begin{tabular}{|c|c|c|c|c|c|c|c|}
\hline & $\begin{array}{l}\text { Linguagem } \\
\text { Pertinência }\end{array}$ & $\begin{array}{l}\text { Linguagem } \\
\text { Clareza }\end{array}$ & $\begin{array}{l}\text { Linguagem } \\
\text { Abrangência }\end{array}$ & $\begin{array}{l}\text { llustração } \\
\text { Pertinência }\end{array}$ & $\begin{array}{l}\text { Ilustração } \\
\text { Clareza }\end{array}$ & $\begin{array}{c}\text { Layout } \\
\text { Pertinência }\end{array}$ & $\begin{array}{l}\text { Layout } \\
\text { Clareza }\end{array}$ \\
\hline Capa e título & 0,96 & 0,88 & 1,00 & 0,96 & 0,88 & 1,00 & 1,00 \\
\hline Apresentação da cartilha & 0,96 & 1,00 & 1,00 & 0,92 & 0,88 & 0,96 & 0,96 \\
\hline $\begin{array}{l}\text { Explicação sobre a incontinência } \\
\text { urinária }\end{array}$ & 1,00 & 0,96 & 0,96 & 0,83 & 0,83 & 0,96 & 0,96 \\
\hline $\begin{array}{l}\text { Explicação sobre fatores } \\
\text { de risco }\end{array}$ & 0,92 & 0,83 & 0,88 & 0,88 & 0,92 & 0,92 & 0,96 \\
\hline $\begin{array}{l}\text { Explicação sobre tipos de } \\
\text { incontinência urinária - esforço }\end{array}$ & 1,00 & 1,00 & 1,00 & 1,00 & 1,00 & 1,00 & 1,00 \\
\hline $\begin{array}{l}\text { Explicação sobre tipos de } \\
\text { incontinência urinária -urgência }\end{array}$ & 0,92 & 0,92 & 0,92 & 0,88 & 0,79 & 1,00 & 1,00 \\
\hline $\begin{array}{l}\text { Explicação sobre tipos de } \\
\text { incontinência urinária -mista }\end{array}$ & 0,96 & 0,92 & 0,96 & 0,92 & 0,88 & 1,00 & 1,00 \\
\hline $\begin{array}{l}\text { Explicação sobre as } \\
\text { consequências da incontinência } \\
\text { urinária para a vida da mulher }\end{array}$ & 1,00 & 1,00 & 1,00 & 1,00 & 1,00 & 1,00 & 1,00 \\
\hline $\begin{array}{l}\text { Conhecendo o corpo feminino - } \\
\text { primeira parte }\end{array}$ & 0,92 & 0,92 & 0,96 & 0,88 & 0,71 & 0,92 & 0,88 \\
\hline $\begin{array}{l}\text { Conhecendo o corpo feminino - } \\
\text { segunda parte }\end{array}$ & 1,00 & 0,88 & 1,00 & 0,96 & 0,96 & 0,96 & 0,96 \\
\hline $\begin{array}{l}\text { Exercícios para melhorar a } \\
\text { condição }\end{array}$ & 0,88 & 0,88 & 0,96 & 1,00 & 1,00 & 0,96 & 0,92 \\
\hline $\begin{array}{l}\text { Exercícios em outras posições - } \\
\text { primeira parte }\end{array}$ & 0,96 & 0,88 & 0,96 & 0,96 & 0,96 & 1,00 & 1,00 \\
\hline $\begin{array}{l}\text { Exercícios em outras posições - } \\
\text { segunda parte }\end{array}$ & 0,96 & 0,88 & 0,96 & 0,96 & 0,96 & 0,96 & 0,96 \\
\hline $\begin{array}{l}\text { Exercício da contração junto à } \\
\text { ponte }\end{array}$ & 0,92 & 0,96 & 0,96 & 0,96 & 0,92 & 1,00 & 0,96 \\
\hline $\begin{array}{l}\text { Exercício da contração junto à } \\
\text { elevação de membros inferiores }\end{array}$ & 0,83 & 0,92 & 0,88 & 0,92 & 0,88 & 0,92 & 0,88 \\
\hline Lembre-se & 0,92 & 0,96 & 0,92 & 0,96 & 0,92 & 0,96 & 0,96 \\
\hline Mudanças de hábitos & 0,92 & 0,92 & 0,96 & 1,00 & 0,96 & 1,00 & 0,96 \\
\hline Lembre-se & 0,96 & 0,92 & 0,92 & 1,00 & 0,96 & 1,00 & 0,96 \\
\hline
\end{tabular}

Valores expressos em IVC.

As usuárias responderam às perguntas (Tabela 2) e afirmaram que a capa da cartilha é chamativa, com sequência de conteúdo e estrutura organizacional adequadas, com conteúdo escrito de modo claro, com texto interessante para a leitura, com frases construídas e ilustrações de fácil entendimento. Em relação a sugestões, apenas duas mulheres sugeriram que a capa da cartilha tivesse cores mais vibrantes e fortes.

Ao final, após todas as correções sugeridas, a cartilha apresentou 24 páginas, com ilustrações e texto, em formato de livreto com dois grampos, conforme mostrado na Figura 1.

Tabela 2. Apontamentos da população-alvo. n=30, SP, (2020)

\begin{tabular}{lc}
\multicolumn{1}{c}{ Perguntas } & \\
Pergunta 1: A capa chamou sua atenção? & $83,3 \%(25)$ \\
Sim & $16,6 \%(4)$ \\
Não & $0,2 \%(1)$ \\
Não sei & $100 \%(30)$ \\
Pergunta 2: A sequência do conteúdo está adequada? & $100 \%(30)$ \\
Sim & $100 \%(30)$ \\
Pergunta 3: A estrutura da cartilha educativa está organizada? & $0(0)$ \\
Sim & $0(0)$ \\
Não & $10)$ \\
Não sei &
\end{tabular}


Tabela 2. Continuação

\section{Perguntas}

Pergunta 4: Quanto ao entendimento das frases, elas são?

Fáceis de entender

$100 \%(30)$

$0(0)$

$0(0)$

Não sei

$100 \%(30)$

Não sei

Pergunta 6: O texto é?

Interessante

Não sei

Pergunta 7: As ilustrações são?

Fáceis de entender

Pergunta 8: As ilustrações servem para complementar o texto?

Sim

Pergunta 9: As páginas ou seções parecem organizadas?

Sim

Pergunta 10: Em sua opinião, qualquer paciente com IU que ler essa cartilha vai entender do que se trata?

Sim

Pergunta 11: Você se sentiu motivado a ler a cartilha até o final?

Sim

Não

Pergunta 12: O material educativo aborda os assuntos necessários para pacientes com IU que realizem os exercícios?

Sim

Pergunta 13: A cartilha educativa Ihe sugeriu a agir ou pensar a respeito da IU?

Sim

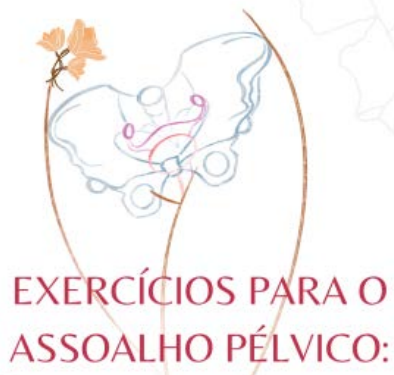

Prevenção e Tratamento da Incontinência Urinária na mulher

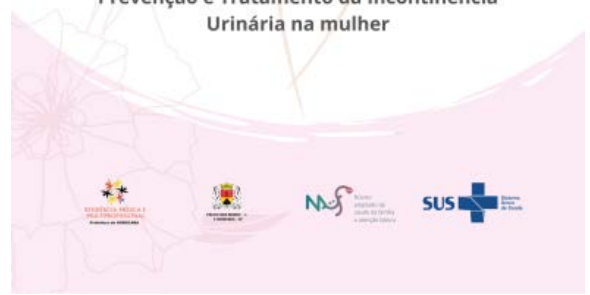

Esta é uma cartilha destinada a mulheres com queixa de perda involuntária de urina, também, conhecido como incontinência urinária.

Este conteúdo demonstra exercícios para os músculos do assoalho pélvico para a prevenção e o tratamento.

\section{FICHA TÉCNICA}

Este material foi produzido na residência multiprofissional Saúde da Família e Comunidade da Prefeitura de Sorocaba (SP).

\section{Concepção e elaboração:}

Iris Bisof Pontes (Fisioterapeuta-Residente) Dra. Uiara Aline de Oliveira Kaizer (Doutora em ciências da saúde e Enfermeira Estomaterapeuta titulada pela Sociedade Brasileira de Estomaterapia- SOBEST)

\section{llustração e Arte:}

Iris Bisof Pontes (Fisioterapeuta-Residente)

Jéssica Carolina Teixeira Lima (Designer) Jamnient (Artista)

É permitida a reproduçăo, desde que citada a fonte.

Edição 1, 2020

Pontes, fris Pisof. Exercicios para o Assolth Patvice: Prevencio Tratamento da Incontinéncis Utinifria na mulher. Programa de Residência Saúde da Familia e Comunidade, Prefeitura de Sorocaba (SP)

Figura 1. Cartilha educativa - versão final (continua) 


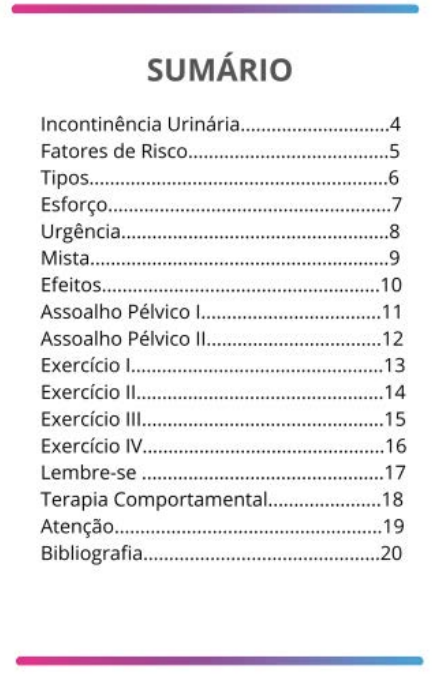

\section{TIPOS DE INCONTINÊNCIA} URINÁRIA

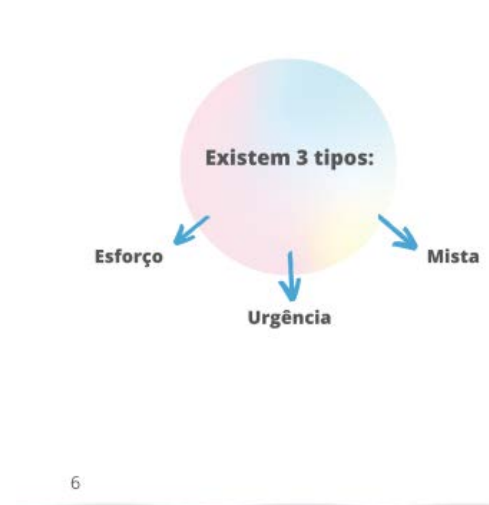

INCONTINÊNCIA URINÁRIA MISTA

É a perda involuntária de urina ao esforço e precedida de um grande desejo de urinar.

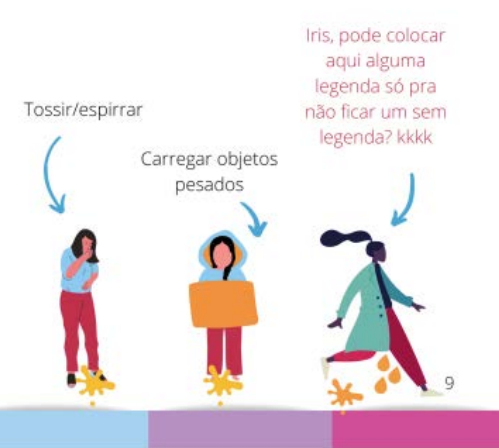

\section{INCONTINÊNCIA URINÁRIA \\ A}

A Sociedade Internacional de Continência define que qualquer perda urinária involuntária já determina uma situação de incontinência urinária

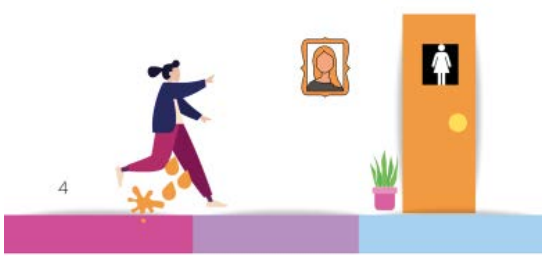

INCONTINÊNCIA URINÁRIA DE ESFORÇO

É aquela que ocorre a perda do xixi quando realizamos algum esforço como tossir, espirrar e levantar objetos pesados.

\section{FATORES DE RISCO}

A Incontinência Urinária pode ocorrer por diferentes causas:

- Excesso de peso corporal

- Consumo excessivo de cafeína

- Hábito de fumar

- Intestino preso

- Menopausa e Envelhecimento

- Alto peso do recém nascido ( $\geq 3.500 \mathrm{Kg}$ )

- Anestesia que prolonga o parto vaginal

- Parto vaginal traumático com lacerações

\section{INCONTINÊNCIA URINÁRIA DE} URGÊNCIA
É a perda involuntária de urina precedida de um forte desejo de urinar.

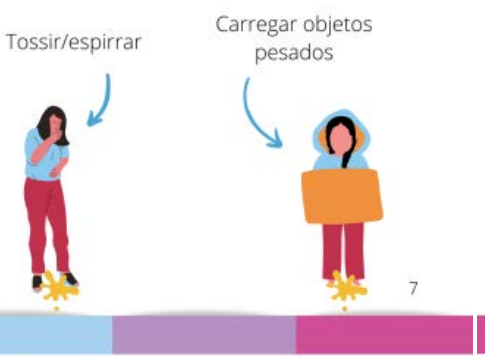

Os efeitos da incontinência urinária na vida das mulheres são muitas..

\section{VAMOS CONHECER OS MÚSCULOS DO ASSOALHO PÉLVICO?}

Figura 1. Cartilha educativa - versão final (continua)

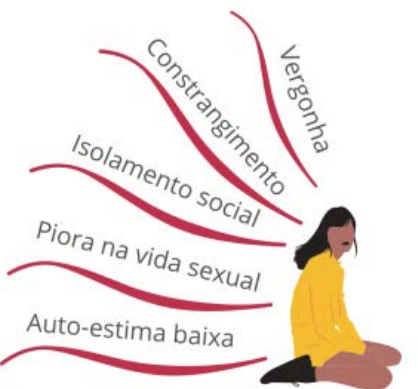

Esses músculos fazem parte da camada muscular profunda da vagina.

Quando a gente coloca um espelho para visualizar a vagina nós conseguimos visualizar:

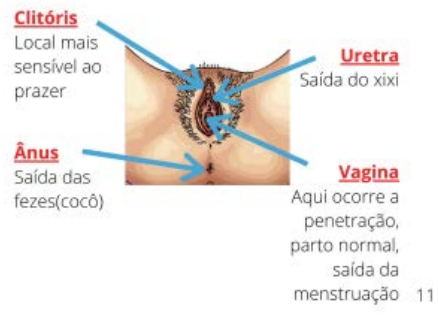




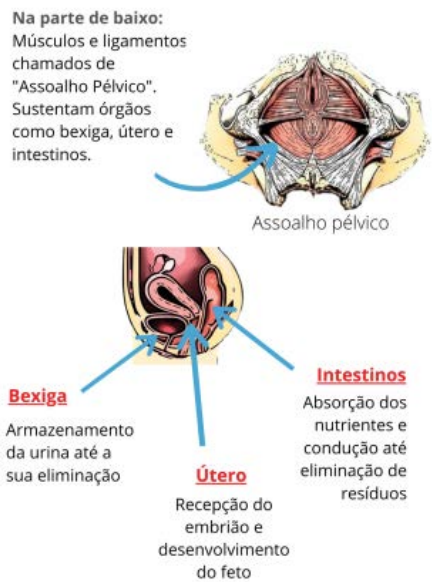

Quando os músculos do assoalho pélvico estão fracos a mulher começa a ter queixas de perda 12 involuntária de urina

Tente realizar este exercício:

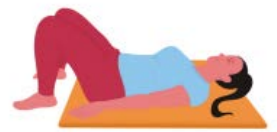

Com o bumbum apoiado no chão contraia os músculos do assoalho pélvico como se tivesse segurando um pum

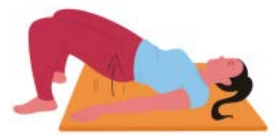

Eleve o quadril ainda segurando o pum, inicial e relaxe por 10 segundos

Realize de 8 a 12 contrações por vez. Preferencialmente realize 3 vezes ao dia

\section{TERAPIA COMPORTAMENTAL}

Podemos mudar alguns hábitos para melhorar a incontinência urinária: Além dos exercicios par necessário realizar mudancas de comportamentos dos nossa rotina de vida para tratar os sintomas de perd de urina.

- Beba água a vontade (não diminua o consumo por conta da incontinência urinária):

- Aumente o consumo de alimentos ricos en

- Controle o peso corporal;

- Lembre-se de realizar a contração quando for

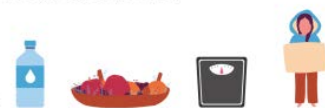

Para melhorar o problema de perda urinária existem exercícios para fortalecer os músculos do assoalho pélvico que podem ser realizados diarimente.

1. Sente na cadeira de um jeito confortável e com os pés no chão

2. Tente contrair os músculos ao redor do ânus, durante a expiração, faça força de segurar cocô contraia também a musculatura como se estivesse segurando o xixi

3. Mantenha a contração de 6 a 10 segundos, descanse por 10 segundos

4. Realize de 8 a 12 contrações por vez

5. Preferencialmente realize 3 vezes ao dia
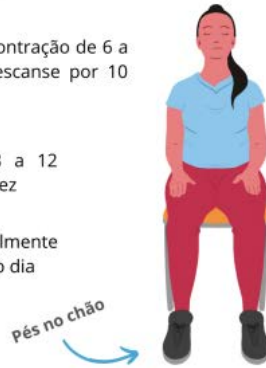

Tente realizar este exercício:

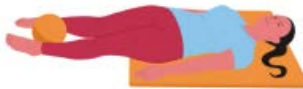

Com uso de uma bola média entre os pé sem apertar, contraia os músculos do assoalho pélvico como se tivesse segurando um pum, com as pernas esticadas no chāo.

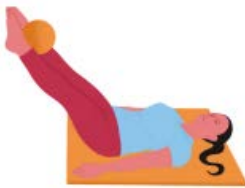

Levante as pernas esticadas ainda fazend a contração. Depois que chegar na altura que conseguir, abaixe as pernas, relaxando.

Realize de 8 a 12 contrações por vez. Preferencialmente realize 3 vezes ao dia
Tente realizar em outras posições a contração do assoalho pélvico aprendida

Você também pode tentar realizar o exercício aprendido na página anterior em outras posições, como por exemplo:
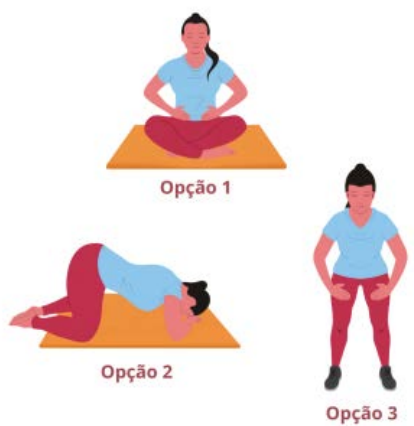

\section{LEMBRE-SE}

Realizar os exercicios de maneira diária é importante. Para não esquecer de fazê-los pode escrever na agenda, no alarme do celular ou se preferir utilize este planejamento mensal, marcando um "X" nos dias que realizou os exercicios.

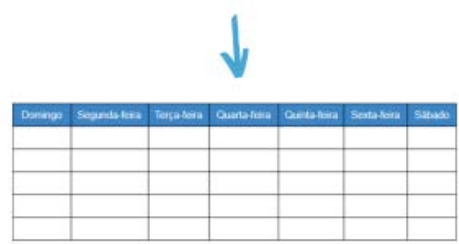

DICA:

Preencha o quadro a lápis para reaproveitar.

\section{ATENÇÃo}

Esta cartilha nāo substitui a avaliação do assoalho pélvico assim como o acompanhamento com um profissional de saúde especializado. Caso voce tenha alguma queixa de perda urinária importante que você procure um profissional de saúde para uma consulta para que ele possa valiar as condiçōes do seu assoalho pélvico e mediar a força dessa musculatura. Sempre que precisar và verificar esta e outras condiçōes de saúde.

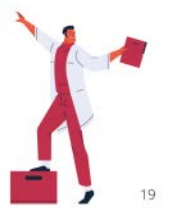

\section{BIBLIOGRAFIA}

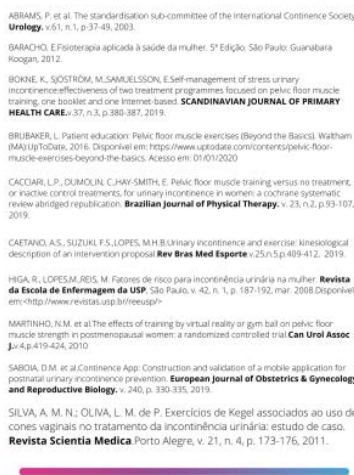

Sus

a.: N.S

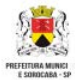

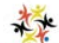

Figura 1. Cartilha educativa - versão final (Continuação) 


\section{DISCUSSÃO}

Para que ocorram sempre a inovação e o fortalecimento da APS, é preciso a incorporação racional de tecnologias de comunicação e educação ${ }^{16}$. Entre elas, destacam-se os materiais educativos impressos nos mais variados formatos, contribuindo para o desenvolvimento da responsabilidade e autonomia dos indivíduos; eles representam alternativas viáveis para informação e sensibilização da população ${ }^{17}$.

Dessa maneira, o primeiro passo para a criação da cartilha educativa foi a busca na literatura especializada. Os aspectos a serem avaliados em mulheres com incontinência urinária são muitos e incluem hábitos de vida e histórico gineco-obstétricos, além do tratamento e da maneira de explicá-los. Isso explica por que é aconselhável um material educativo com questões que possam auxiliar às mulheres e definir conceitos e cuidados importantes, como a capacidade de contribuir para a prevenção das complicações das que têm IU, a fim da melhoria das condutas terapêuticas ${ }^{18}$.

Com vistas a salvaguardar as informações da cartilha e também a criação dela, é relevante a multidisciplinaridade dos juízes que participaram do seu processo avaliativo. Isso reflete a valorização das opiniões e das perspectivas de que o trabalho em equipe sobre a área temática e de construção do material educativo é uma possibilidade de alinhar condutas ao cuidado no paciente com a participação dos profissionais de saúde ${ }^{19}$.

A linguagem direcionada para materiais educativos deve ser clara e simples - o ideal é que seja compreensível para pessoas com idade de 10 a 14 anos; já o layout e a ilustração precisam ser legíveis, de fácil compreensão, eficazes e culturalmente relevantes ${ }^{11,18}$. A exemplo disso, um dos juízes solicitou a substituição de uma das ilustrações por outra, mais representativa; já outro apontou a necessidade de troca de uma das figuras por uma melhor representação da mulher com IU, além até da substituição da imagem da capa e a inserção de um novo título.

O procedimento de adaptação da cartilha educativa com as sugestões dos juízes é um passo fundamental para torná-la mais integral, com rigor científico e efetiva no processo de educação em saúde ${ }^{18}$. Foram sugeridas a (re) elaboração e a exclusão de fragmentos, a substituição de termos e a concepção das ilustrações.

Assim, após a avaliação dos especialistas - e mesmo que o IVC fosse considerado adequado, e as sugestões, vistas como melhorias -, o que foi apontado por eles foi acatado de forma mais clara. $\mathrm{O}$ material educativo foi reformulado de maneira simples, com escrita concisa, possibilitando a transmissão de informações precisas para que os leitores apresentassem melhor aprendizagem em relação ao assunto abordado. Essas alterações realizadas na cartilha proporcionaram modificações significativas visando ao aprimoramento do material, conforme perspectivas dos juízes e dos pesquisadores.

Em relação às figuras, que também foram reformuladas, a literatura aponta que estas devem ser atraentes, com comunicação não verbal objetiva e clara para despertar o interesse do público e a aceitação nos diversos níveis de escolaridade ${ }^{18}$.

Ademais, um dos juízes sugeriu modificações quanto ao protocolo de exercícios, as quais foram acatadas. Elas vão ao encontro do que defende a literatura, ou seja, de que se tenha a contração perineal de 8 a 12 vezes em cada sessão de exercícios e que seja realizado, se possível, três vezes ao dia por um período de 15 a 20 semanas de treinamento ${ }^{20}$. Tais exercícios também são conhecidos como perineais e se caracterizam por ser de simples execução, sendo necessárias a participação ativa e a motivação das pacientes ${ }^{11}$.

Em relação à contribuição dos juízes para a construção e validação da cartilha educativa, a concordância entre eles na pesquisa foi de 0,80 para os itens. Isso corrobora outro estudo de criação de tecnologia de informação, utilizando um aplicativo para smartphones com o público-alvo de mulheres com IU após o parto, que obteve IVC maior do que $0,80^{9}$.

Por outro lado, um estudo sobre a concepção e desenvolvimento de um material educativo para mulheres com IU não utilizou a ferramenta IVC, e sim uma média das variáveis (linguagem, ilustração e apresentação de informação), recorrendo a uma escala do tipo Likert e envolvendo apenas quatro juízes para a validação ${ }^{3}$.

A utilização do público-alvo no processo de construção e validação da cartilha educativa permite caracterizar e identificar a quem se destina, bem como indicar se o conteúdo do material atende às demandas estabelecidas $^{21}$.

Em relação ao público-alvo, verifica-se que no estudo de Mourão e colaboradores ${ }^{22}$ foi realizada a caracterização de 48 mulheres atendidas por uma clínica ginecológica que tinham o seguinte perfil: prevalência de IU na faixa etária de 30 a 48 anos, ensino médio completo, quatro ou mais filhos, sem constipação intestinal, consumo de cafeína e sem hábitos tabagistas. Isso corrobora parcialmente com os dados do presente estudo: incidência de IU na faixa etária de 30 a 49 anos, ensino médio completo, dois filhos, histórico de parto cesáreo, IMC entre 25,0 
e 29,9, sem constipação intestinal e hábitos tabagistas e com consumo de cafeína.

A prevalência de mulheres na faixa etária de 30-49 anos que expressaram a IU corrobora os dados encontrados na literatura, visto que a incidência da patologia cresce com o processo de envelhecimento - a ocorrência de IU tende a ser menor em mulheres jovens e adultas jovens ${ }^{23}$. Já o excesso de peso corporal com elevado IMC aumenta a pressão intra-abdominal nas atividades do cotidiano, o que resulta em uma elevação da pressão vesical e maior mobilidade da uretra, levando à perda urinária ${ }^{24}$.

Durante a fase do pré-teste, a amostra populacional de 30 mulheres compreendeu imagens e texto. Entre as participantes, $83,3 \%$ julgaram a capa como chamativa, todas concordaram que a sequência, a estrutura organizacional e o entendimento das frases estavam adequadas, que o texto era interessante e com escrita clara, e que as ilustrações foram fáceis de entender e serviam de complemento. Quanto à abordagem dos assuntos necessários na cartilha, $100 \%$ disseram que foram totalmente abordados e que estimularam a reflexão; a grande maioria $(96,6 \%)$ teve motivação para ler o material.

Considerando-se o conceito da pedagogia em relação à inclusão do indivíduo, o uso de cartilhas como tecnologia de educação em saúde evidencia a postura humanista de respeito às diferenças, entendimento das singularidades e equidade na oportunidade do acesso ao cuidado para todos. Trata-se de um recurso palpável, atemporal, de acesso fácil e de ampla aplicabilidade para o público a que se destina, com utilização possível até mesmo em âmbito domiciliar. Além disso, a comunicação escrita facilita o processo de educação sobre o tema, permitindo a decodificação e a assimilação da informação com uso de linguagem clara, com exemplos, que, adicionados às ilustrações, possibilitam ao leitor/paciente a formação de uma consciência crítica e também orientada para uma vida mais saudável, com maior autonomia, protagonizando assim o autocuidado ${ }^{25}$.

Os materiais educativos na APS devem ser utilizados como apoio complementar, além de serem de fácil aquisição e manuseio pelos usuários do $\mathrm{SUS}^{26}$. Dessa maneira, é necessário que sejam ofertados nas práticas educativas no âmbito da saúde, porém, isso não pode ser feito como substituição ao processo comunicativo e clínico que precisa existir entre profissional de saúde e paciente. A construção e validação de uma cartilha para IU em mulheres no âmbito da atenção básica constitui um grande incentivo para ações voltadas à promoção de saúde, bem como processos reabilitadores e preventivos nessa população ${ }^{3}$.
A confecção e validação da cartilha educativa perpassou pelas etapas necessárias recomendadas na literatura. Tal fato permite que o material construído seja utilizado por distintos profissionais da saúde que trabalhem com essa população, destacando a importância de orientações de promoção e prevenção de agravos da IU, além do tratamento.

No âmbito científico, a cartilha pode ser utilizada entre a população feminina em distintos aspectos, visando à sua aplicabilidade, bem como à efetividade e adesão das pacientes para o autocuidado.

\section{CONCLUSÃO}

Conclui-se que a cartilha educativa Exercicios para o assoalho pélvico: prevenção e tratamento da incontinência urinária na mulher apresentou boa validade de conteúdo. Após todas as etapas de construção e validação, o instrumento se revelou adequado para ser utilizado na Atenção Primária à Saúde pelo seu conteúdo coerente com a realidade e com a necessidade de saúde, elencando os principais aspectos a serem visualizados pelo profissional de saúde nessa avaliação.

\section{REFERÊNCIAS}

1. Abrams P, Cardozo L, Fall M, Griffiths D, Rosier P, Ulmsten U, et al. The standardisation of terminology in lower urinary tract function: report from the sub-committee of the International Continence Society. Urology. 2003;61(1):37-49.

2. Baracho E. Fisioterapia aplicada à saúde da mulher. 6th ed. Rio de Janeiro: Guanabara Koogan; 2018.

3. Oliveira AHAM, Vasconcellos TB, Macena RHM, Bastos VPD. Cartilha educativa para mulheres sobre incontinência urinária: concepção e desenvolvimento. Rev Baiana Saude Publica. 2017;41(2):308-23.

4. Castañeda BI, Martínez TJC, García DJA, Rodríguez AEM, Pérez RNM. Aspectos epidemiológicos de la incontinencia urinaria: revisión bibliográfica. Rev Cub Med Fis Rehab [Internet]. 2016;8(Suppl:1):88-98. [cited 2020 Jan 10]. Available from: https://bit.ly/3zPMnJ9

5. Tavares LRC, Costa JLR, Oishi J, Driusso P. Inserção da fisioterapia na atenção primária à saúde: análise do Cadastro Nacional de Estabelecimentos de Saúde em 2010. Fisioter Pesqui. 2018;25(1):9-19. doi: 10.1590/1809-2950/15774625012018.

6. Maia FSE, Moura ELR, Madeiros EC, Carvalho RRP, Silva SAL, Santos GR. A importância da inclusão do profissional fisioterapeuta na atenção básica de saúde. Rev Fac Cienc Med Sorocaba [Internet]. 2015;17(3):110-5. [cited 2020 Jan 10]. Available from: https://bit.ly/2WF5OpK 
7. Saboia DM, Vasconcelos CTM, Oria MOB, Firmiano MLV. Aplicativo educativo para prevenção da incontinência urinária - etapas de construção. Proceedings of the 3 rd JOIN; 2017 Oct 12-14; Fortaleza. Fortaleza: Universidade Estadual do Ceará; 2017.

8. Lunardi ALB, Vera MAV. Elaboração de cartilha educativa sobre o assoalho pélvico e sua relação com a incontinência urinária [Internet]. Proceedings of the 4th Congresso Brasileiro de Fisioterapia em Saúde da Mulher; 2018 May 30-Apr 1; Belo Horizonte. Belo Horizonte: COBRAFISM; [cited 2020 Jan 10]. Available from: https://bit.ly/3ifq8X0

9. Polit DF, Beck CT. Nursing research: generating and assessing evidence for nursing practice. Philadelphia: Wolters Kluwer; 2016.

10. Hoffmann T, Warrall L. Designing effective written health education materials: considerations for health professionals. Disabil Rehabil. 2004;26(9):1166-73.

11. Alexandre NMC, Coluci MZO. Validade de conteúdo nos processos de construção e adaptação de instrumentos de medida. Cienc Saude Colet. 2011;16(7):3061-8. doi: 10.1590/ S1413-81232011000800006.

12. Medeiros RKD, Ferreira MA Júnior, Torres GV, Vitor AF, Santos VEP, Barichello E. Validação de conteúdo de instrumento sobre a habilidade em sondagem nasogástrica. Rev Eletronica Enferm. 2015;17(2):278-89. doi: 10.5216/ree.v17i2.28820.

13. Haynes SN, Richard DCS, Kubany ES. Content validity in psychological assessment: a functional approach to concepts and methods. Psychol Assess. 1995;7(3):238-47.

14. Joventino EM. Construção e validação de escala para mensurar a autoeficácia materna na prevenção da diarreia infantil [master's thesis]. Fortaleza: Universidade Federal do Ceará; 2010.

15. Galdino YLS. Construção e validação de cartilha educativa para o autocuidado com os pés de pessoas com diabetes [master's thesis]. Fortaleza: Universidade Federal do Ceará; 2014.

16. Tasca R, Massuda A, Carvalho WM, Buchweitz C, Harzheim E. Recomendações para o fortalecimento da atenção primária à saúde no Brasil. Rev Panam Salud Publica. 2020;6(44):1-8. doi: 10.26633/RPSP.2020.4.
17. Gonçalves MS, Celedônio RF, Targino MB, Albuquerque TO, Flauzino PA, Bezerra NA, et al. Construção e validação de cartilha educativa para promoção da alimentação saudável entre pacientes diabéticos. Rev Bras Prom Saúde. 2019;32(1):77-81. doi: 10.5020/18061230.2019.7781.

18. Lima ACMACC, Bezerra KC, Sousa DMN, Rocha JF, Oriá MOB. Construção e validação de cartilha para prevenção da transmissão vertical do HIV. Acta Paul Enferm. 2017;30(2):181-91. doi: 10.1590/1982-0194201700028.

19. Oliveira SC, Lopes MVO, Fernandes AFC. Construção e validação de cartilha educativa para alimentação saudável durante a gravidez. Rev Latinoam Enferm. 2014;22(4):611-20. doi: 10.1590/0104-1169.3313.2459.

20. Brubaker L, editor. Uptodate. Educação do paciente: exercícios para os músculos do assoalho pélvico (além do básico); 2016.

21. Alves AM. Construção e validação de cartilha educativa para prevenção de quedas em idosos [master's thesis]. Fortaleza: Universidade Federal do Ceará; 2017.

22. Mourão LF, Luz MHBA, Marques ADB, Benício CDAV, Nunes BMVT, Pereira AFM. Caracterização e fatores de risco de incontinência urinária em mulheres atendidas em uma clínica ginecológica. Estima. 2017;15(2):82-91. doi: 10.5327/ Z1806-3144201700020004.

23. Patrizzi LJ, Viana DA, Silva LMA, Pegori MS. Incontinência urinária em mulheres jovens praticantes de exercício físico. Rev Bras Cienc Mov. 2014;22(3):105-10. doi: 10.18511/0103-1716/ $\mathrm{rbcm}$.

24. Oliveira E, Lozinsky AC, Palos CC, Ribeiro DDAM, Souza AMB, Barbosa CP. Influência do índice de massa corporal na incontinência urinária feminina. Rev Bras Ginecol Obstet. 2010;32(9):454-8. doi: 10.1590/S0100-72032010000900007.

25. Albuquerque AFLL. Tecnologia educativa para promoção do autocuidado na saúde sexual e reprodutiva de mulheres estomizadas: estudo de validação [master's thesis]. Recife: Universidade Federal de Pernambuco; 2015.

26. Bezerra IC, Silva RM, Bedê JB, Castro PCR, Brasil CCP, Pinheiro CPO. Tecnologia educativa para gestantes: construção e avaliação de cartilha. Cuba Salud. 2018;11(2):1-5. 